\title{
Smart Community Electric Energy Micro-Storage Systems with Active Functions
}

\author{
M. Isabel Milanes-Montero \\ University of Extremadura \\ Escuela de Ingenierías Industriales \\ Avda. de Elvas s/n \\ 06006 Badajoz, Spain \\ milanes@unex.es
}

\author{
Fermin Barrero-Gonzalez \\ University of Extremadura \\ Escuela de Ingenierías Industriales \\ Avda. de Elvas s/n \\ 06006 Badajoz, Spain \\ fbarrero@unex.es
}

\author{
Jaime Pando-Acedo \\ PE\&ES R\&D Group \\ Escuela de Ingenierías Industriales \\ Avda. de Elvas s/n \\ 06006 Badajoz, Spain \\ jpandoac@peandes.es
}

\author{
Eva Gonzalez-Romera \\ University of Extremadura \\ Escuela de Ingenierías Industriales \\ Avda. de Elvas s/n \\ 06006 Badajoz, Spain \\ evagzlez@unex.es
}

\author{
Enrique Romero-Cadaval \\ Senior Member IEEE \\ University of Extremadura \\ Avda. de Elvas s/n \\ 06006 Badajoz, Spain \\ eromero@unex.es
}

\author{
Antonio Moreno-Munoz \\ Senior Member IEEE \\ Computer Architecture, Electronics and \\ Electronic Technology Department \\ Universidad de Córdoba \\ Córdoba, Spain \\ a.moreno@ieee.org
}

\begin{abstract}
Smart grids aim to dramatically change residential area energy systems by creating active grid interaction. Specifically, renewable energies will play a key role when it comes to handle Energy Storage Systems (ESS) at houses within a Smart Community. This paper presents a novel global control strategy for distributed micro-storage energy system. Each home receives the active and reactive power set- points from the Smart Community Energy Management System (SCEMS), providing energy resources to the community in function of the expected demand and production. Once SCEMS requirements are fulfilled, harmonic current components demanded by the household circuitry are injected according to the ESS available capacity. The proposed approach not only causes a local improvement in the power quality of the demanded current, but also contributes to the global power quality consumption of the community. Experimental tests are conducted using a prototype of the proposed ESS charger, validating the control strategies.
\end{abstract}

Index Terms-Active Functions; Battery chargers; Energy Storage; Energy Management; Harmonic control; Microstorage systems; Smart Communities.

\section{INTRODUCTION}

The so called Smart Communities [1]-[2] take advantage of distributed generation based on renewable energies to efficiently supply an increasing electric energy demand, thanks to the great advance in energy storage systems research.

Consumers could obtain benefits in terms of savings in their energy bills [3], since some of the energy they need could be provided by the distributed generators of the community, either directly (if the time-period of consumption matches that of the non-manageable energy production) or indirectly by means of energy storage systems, with a proper management.

Advantages for the owners of distributed energy resources also arise. Distributed generation located near consumers are usually non-manageable (photovoltaic or wind units) [4]. Therefore, coordination with consumers and storage systems allows them to sell their energy locally or to sell it to market in high-price time periods, independently of the generation timetable [5].

Finally, demand side management and smoothing of renewable energy injection obviously constitute a great advantage for the operation of the distribution grid [6]-[7].

In this context, Energy Storage Systems (ESS) are key elements for the energy management system of the smart community [8]-[9]. Scientific literature pays most of the attention to the research on the design of large storage capacity (10-100 MWh) equipment [10]. However, recently research has been focused on distributed micro-storage systems, with a capacity of few $\mathrm{kWh}$ [11]. Installed in homes, these micro-storage systems would allow consumers to store a small amount of energy locally, taking over demand peaks and intermittency and variability of renewable energy sources supply. The control of this equipment is performed by a central Smart Community Energy Management System (SCEMS). It acts as an aggregator of resources and coordinates them to assure benefits for every community stakeholders. A simulation of different scenarios of photovoltaic energy penetration and battery size in a 8 houses neighbourhood is performed in [12], concluding that noticeable cost savings and income improvements are obtained when they operate as a coordinated energy community. Among other functions, the SCEMS is responsible for generating set-points of both active and reactive power and sending them to each local ESS for charging/discharging, based on the expected demand and production.

In addition, harmonic currents and reactive power [13] demanded by most battery chargers for ESS on the market, would impact in the power quality of the distribution system, 
in case of massive penetration [14]-[15]. Therefore, research in new control strategies applicable to the Energy Storage Management System (ESMS) is required to guarantee that these chargers operate in consonance with the smart grid goals [16].

Besides, the DC/AC converter that constitutes the ESS charger could be used to provide further active function to the grid, as active power filtering [17]-[18]. If each local ESS in a Smart Community partially or totally injects the harmonic currents demanded by the home they are located in, a global improvement of the power quality could be achieved.

Most bidirectional chargers found in the technical literature focus on the active power flow control [19] and few works address a reactive power flow control [20-21]. However, the benefits of including a local harmonic control strategy, operating simultaneously with the active and reactive controllers, have not been thoroughly investigated. Following this research line, [22] provides control strategies for the ESMS of the micro-storage device, to fulfil the set-points received from the SCEMS. These strategies allow control of the active power ( $P$ mode), and reactive power ( $Q$ mode) flows. Besides, harmonic control $(H$ mode) is also proposed, compensating the harmonic consumption of the home. In [22] it is confirmed by simulation that the strategies improved the ESS performance and the power quality of the charger current under normal and abnormal grid conditions. This paper takes one more step, aiming to contribute to the validation of these proposed control strategies by using an experimental prototype of a local ESS. The objective is to demonstrate experimentally that a bidirectional charger can provide active functions to the smart community grid. Some tests have been carried out, showing experimental results of the local microstorage system operation in a smart community with distributed energy resources.

The main contributions of the paper are: the proposal and experimental validation of a global control strategy which allows the charger to operate simultaneously with $P, Q$ and $H$ control, and the harmonic control strategy with saturated function, to assure the charger safety.

The paper is organized as follows: the first two sections are devoted to the explanation of the active functions control strategies: in section II the active power and reactive power control strategies are proposed, while the harmonic control strategy is presented in section III. The experimental prototype is explained in section IV, showing the charger topology and control stage. Experimental results are displayed in section V. Finally, conclusions are summarized in section VI.

\section{ACTIVE AND REACTIVE POWER CONTROL STRATEGIES}

\section{A. Active Power}

The smart community has carried out a market strategy considering the expected demand and production, the State of Charge (SOC) of the distributed micro-storage systems and the energy prize. From this start point, the SCEMS will manage the local ESS at homes, by sending an active power set-point to each individual ESS. Two modes of operation can be distinguished: Grid to Battery mode (G2B-P mode) when the ESS is extracting active power to charge the batteries, and Battery to Grid mode (B2G-P mode), when the ESS is injecting active power from the batteries into the grid. The sign criterion for the set-point is positive in the G2B-P mode $\left(P_{r e f}>0\right)$, and negative in the B2G-P mode $\left(P_{r e f}<0\right)$.

Among other possibilities, it is proposed a Sinusoidal Current (SC) control strategy [23]. It aims to control the charger converter in such a way that the demanded or injected current into the grid is in phase with the fundamental component of the grid voltage. This assures that the ESS will operate with unity displacement Power Factor $(d P F)$ and, at the same time, the charger current will have no harmonic content. The reference charger current is [23]:

$$
i_{c h-P, r e f}=\frac{P_{r e f}}{U_{S 1}^{2}} u_{S 1 d},
$$

where $U_{S 1}$ is the RMS fundamental component of the grid voltage and $u_{S 1 d}$ is the instantaneous value of this component.

A single-phase Autoadjustable Synchronous Reference Frame (ASRF) [24] is employed to extract the fundamental component of the grid voltage.

\section{B. Reactive Power}

It is also possible to provide voltage support at the PCC to which the community is connected; or the improvement of the global power factor of the community might be convenient. Both cases would be motivated by economical reason based on the tariffs applicable by the supply company. It has been already proved how a proper active power control in community energy storage can contribute to improve VoltVar Optimization (VVO) solutions [25]. In this paper, it is pointed out that the storage power conversion system could also improve the impact in VVO solutions by injecting reactive power through a 4-quadrant inverter. However, this reactive power injection is not simulated in [25].

Taking these goals into account, the SCEMS calculates a fundamental reactive power set-point, $Q_{1 \text { ref, for each }}$ individual ESS. The modes of operation are: G2B-Q mode, when the ESS is absorbing fundamental reactive power from the grid, so $Q_{1 r e f}>0$, and B2G-Q mode, when $Q_{1 r e f}<0$, since the battery is injecting fundamental reactive power to grid.

A Quadrature Sinusoidal Current (QSC) control strategy proposed in [22], equivalent to the previous SC strategy, is applied in this case. This strategy aims to control the charger in such a way that the current demanded or injected into the grid is sinusoidal, and in quadrature with the fundamental component of the grid voltage, achieving a null $d P F$. The reference charger current with this strategy is obtained as:

$$
i_{c h-Q, r e f}=\frac{Q_{1 r e f}}{U_{S 1}^{2}} u_{S 1 q} .
$$

where $u_{S 1 q}$ is the instantaneous value of the fundamental component of the grid voltage, being $+90^{\circ}$ phase shifted from $u_{S 1 d}$. This component can be calculated by using the singlephase ASRF proposed in [24]. 


\section{AdDitional ACtive FunCtion: Harmonic CONTROL STRATEGY}

If the ESS is below 100\% capacity, it can be in charge of an additional active function concerning the power quality improvement of the current demanded by each home and so, contributing to the global power quality consumption of the community. Unlike a traditional active power filter, which is specifically designed and controlled to reduce the harmonic distortion caused by a nonlinear load, this is a secondary function for the charger. The harmonic control only comes into operation once the ESMS verifies that the ESS has available capacity and, if necessary, saturates the harmonic load current compensation to ensure that the charger does not exceed its nominal parameters.

This harmonic control function has only a unidirectional operation mode, from the charger to the home: Battery to home mode (B2H-H mode).

A Total Harmonic Compensation (THC) control strategy is proposed. It aims to provide as harmonic reference charger current the whole harmonic spectrum of the current demanded by the house, neglecting the fundamental frequency. The advantage of this strategy, comparing to selective harmonic compensation strategies [26], is that it can be applied for loads with unknown harmonic spectrum and requires simpler control algorithms.

This reference current has to be limited to prevent overload, that is to say, the nominal current of the charger, $I_{c h, n}$, must not be exceeded. Therefore, the maximum RMS harmonic charger current is obtained as:

$$
I_{c h-H, \max }=\sqrt{I_{c h, n}^{2}-I_{c h-P}^{2}-I_{c h-Q}^{2}},
$$

where $I_{c h-P}$ and $I_{c h-Q}$ are the RMS reference charger current components responsible for the $P$ and $Q$ control, obtained from (1) and (2), respectively. The reference harmonic charger current can be calculated as:

$$
i_{c h-H, \text { ref }}=-\left(i_{L}-i_{L 1}\right),
$$

where $i_{L}$ is the total load current demanded by the house and $i_{L 1}$ its fundamental component, obtained from a Synchronous Reference Frame (SRF) operating with the fundamental phase angle delivered by the single-phase ASRF [24].

This current has to be limited to the maximum RMS harmonic charger current, $I_{c h-H, \max }$, obtained from (3). The resulting reference harmonic charger current will be given by the following expression:

$$
\begin{array}{ll}
i_{c h-H, r e f}^{s a t}=i_{c h-H, r e f} & \text { if } I_{c h-H, r e f} \leq I_{c h-H, \text { max }} \\
i_{c h-H, r e f}^{s a t}=\frac{i_{c h-H, r e f}}{I_{c h-H, r e f}} I_{c h-H, \text { max }} & \text { if } I_{c h-H, r e f}>I_{c h-H, \text { max }}
\end{array}
$$

where, $I_{c h-H, r e f}$ is the RMS value of $i_{c h-H, r e f}$.

\section{EXPERIMENTAL PROTOTYPE}

An experimental prototype of a $1 \mathrm{kVA}$ ESS charger has been developed to test the proposed active functions control strategies. This charger is connected to a single-phase $230 \mathrm{~V}$ grid, so the nominal charger current, $I_{c h, n}$ is $4.35 \mathrm{~A}$.

The topology of this charger is displayed in Fig. 1. It is the most usual topology for bidirectional single-phase chargers [23] and consists of a DC/DC converter and an inverter sharing a common DC bus. Inductive filters are used to connect the ESS to the DC/DC converter, with inductance $L_{D C}$ and internal resistance $R_{D C}$, and the DC/AC converter to the grid, with inductance $L_{A C}$ and internal resistance $R_{A C}$. Besides, a non-linear load is included in the experimental setup to validate the $H$ mode operation of the ESS charger. This load is a single-phase non-controlled rectifier with a capacitive filter $C_{L}$ and resistive load $R_{L}$. A filter inductor with inductance $L_{L}$ is used to connect the load to the grid. The parameters of the prototype and non-linear load are summarized in Table I.

The control platform is also shown in Fig. 1, with the measuring nodes and the inputs and outputs of the control stage.

The global control strategy of the charger is shown in Fig. 2. There are independent blocks to implement the SC strategy using (1), the QSC strategy from (2) and the THC strategy employing (5). The reference charger current is obtained by adding the components responsible for the active $P$ mode, reactive $Q$ mode and harmonic $H$ mode controls. A singlephase ASRF is applied to extract the components $u_{S 1 d}$ and $u_{S 1 q}$ and the fundamental phase angle $\theta_{1}$ of the grid voltage, used as an input of the single-phase SRF employed to obtain the fundamental load current.

As can be seen from Fig. 2, the global control strategy needs to measure the grid voltage and the load current. The inputs, highlighted in grey, are the set-points provided by the SCEMS and the nominal charger current, $I_{c h, n}$. The output of the control block is the reference charger current.

The control strategy of the DC/DC converter is displayed in Fig. 3. The reference battery current is obtained by adding two terms: the main term is calculated as the current required to meet the active power balance on the side of the battery, neglecting the losses:

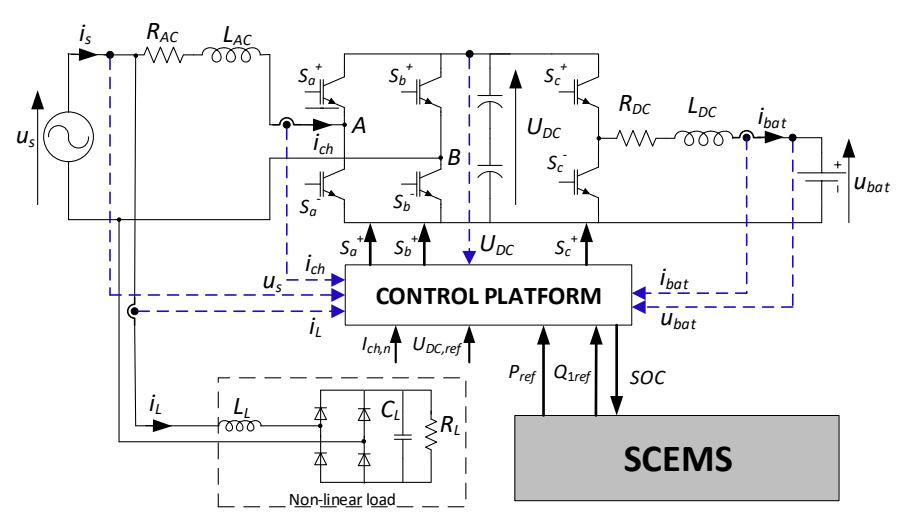

Fig. 1. Topology and control stage of the experimental setup: ESS charger and non-linear load. 
TABLE I

PARAMETERS OF THE EXPERIMENTAL SETUP

\begin{tabular}{lll}
\hline Parameter & Symbol & Value \\
\hline Nominal grid voltage & $U_{S}$ & $230 \mathrm{~V}$ \\
Reference DC bus voltage & $U_{D C, r e f}$ & $500 \mathrm{~V}$ \\
Inductance DC/AC filter & $L_{A C}$ & $8.4 \mathrm{mH}$ \\
Resistance DC/AC filter & $R_{A C}$ & $1.34 \Omega$ \\
Inductance DC/DC filter & $L_{D C}$ & $15 \mathrm{mH}$ \\
Resistance DC/DC filter & $R_{D C}$ & $0.38 \Omega$ \\
Non-linear load capacity & $C_{L}$ & $1.8 \mathrm{mF}$ \\
Non-linear load resistance & $R_{L}$ & $110 \Omega$ \\
Inductance load filter inductor & $L_{L}$ & $4.2 \mathrm{mH}$ \\
\hline
\end{tabular}

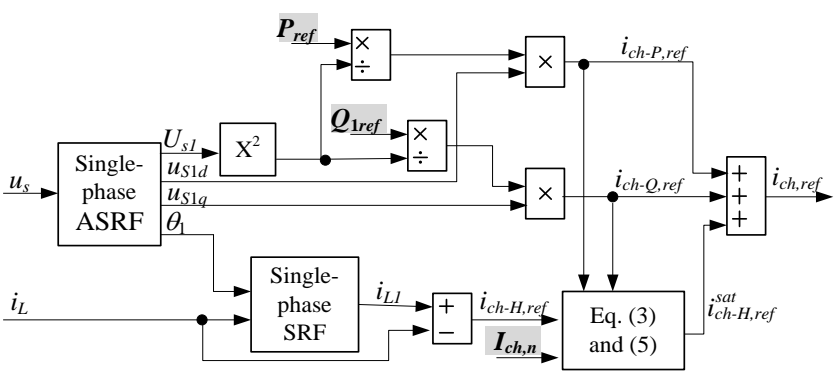

Fig. 2. Block diagram of the general control strategy ( $P, Q$ and $H$ control).

$$
i_{b a t, r e f}=\frac{P_{r e f}}{u_{B a t}}
$$

the other term is calculated from a Proportional-Integral (PI) controller to regulate the DC bus voltage to its reference value, $U_{D C, \text { ref, }}$, and also to add the current increase needed to overcome the power losses in the transfer of energy between the grid and the battery. Thus, the active power set-point is met on the grid side, but fits on the side of the battery, being higher than $P_{r e f}$ when the system is discharging and lower than $P_{\text {ref }}$ when the system is charging. The PI controller is responsible for adjusting this second term depending on the operating conditions of the system.

The bidirectional DC/DC control strategy needs to measure the battery voltage and the DC bus voltage and to receive the inputs highlighted in grey in Fig. 3: the active power set-point provided by the SCEMS and the reference DC bus voltage. The output is the reference battery current.

Dead beat controllers are used to generate the switching signals of the converters, aiming to reduce to zero the error between the reference and measured charger current and battery current, respectively, in each switching period. The switching frequency has been fixed to $5 \mathrm{kHz}$ in both converters. Finally, considering the control strategies and tracking techniques, the six variables which must be measured to control the energy micro-storage prototype are (see the measuring nodes in Fig. 1): the DC bus voltage, battery voltage and grid voltage, the charger current, load current and battery current. Fig. 1 also includes the control stage. The inputs for this block are these six measurements from the sensor board, and the set-points $P_{\text {ref }}$ and $Q_{1 \text { ref }}$ from the SCEMS. The nominal charger current $I_{c h, n}$ and reference DC bus voltage, $U_{D C \text {, ref }}$, are also input parameters for the control algorithms. The outputs of the control stage are the switching signals $S_{a}{ }^{+}$and $S_{b}{ }^{+}$for the DC/AC converter, the switching signal $S_{c}{ }^{+}$for the DC/DC converter, and the SOC of the battery, which is sent to the SCEMS.

In Fig. 4 a photograph of the experimental prototype is shown. The bidirectional grid emulator Cinergia GE15 is employed to test the charger under sinusoidal and distorted voltage conditions. The power module used to implement the DC/DC and DC/AC converters of the charger topology shown in Fig. 1 is SEMIKRON SEMITEACH-IGBT. The control platform is dSPACE DS1104 and the sensor board has been built with 3 Hall-effect voltage sensors LV25-P and 3 Halleffect current sensors LA55-P. The storage system is a BMZ ESS 3.0 Li-Ion battery module, $55.5 \mathrm{~V}, 97.2 \mathrm{Ah}$.

\section{EXPERIMENTAL RESULTS}

In this section, four experimental tests conducted to support the individual and global control strategies of the ESS charger prototype, under distorted and sinusoidal grid voltage conditions, are presented.

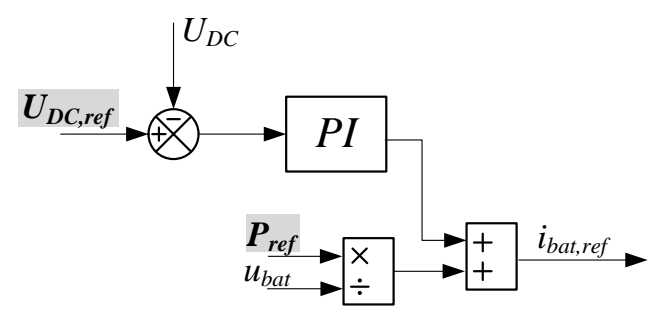

Fig. 3. Block diagram of the DC/DC control strategy.

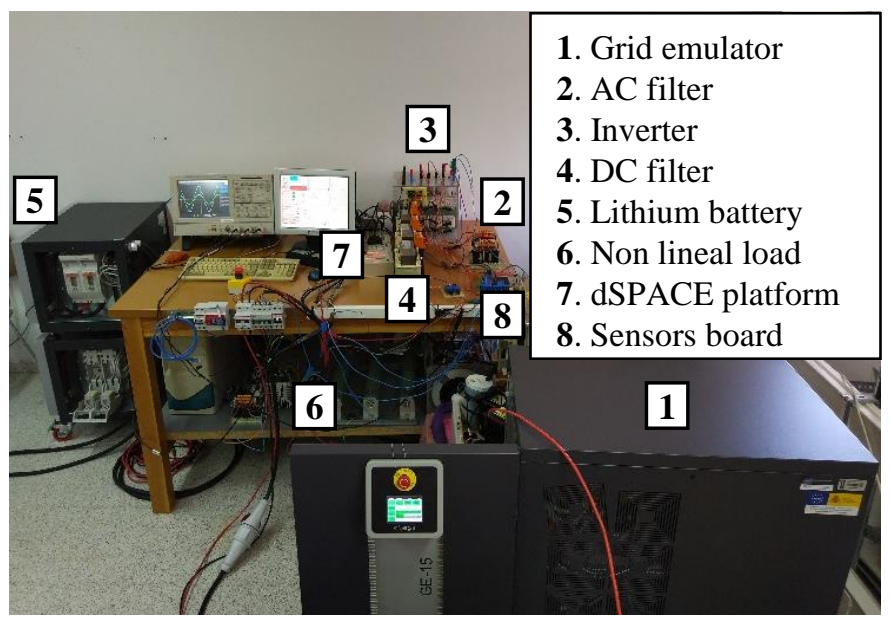

Fig. 4. Photograph of the experimental prototype. 
The Fluke 435 Power Quality Analyzer has been used to measure the power terms provided by the charger, in order to validate the $P$ and $Q$ control. The active and fundamental reactive power, as well as the RMS charger current, $I_{c h}$, the apparent power, $S$, the displacement power factor, $d P F$ and power factor, $P F$, obtained in each test are collected in Table II. Harmonic spectra of the load, charger and source currents have also been acquired and summarized in Table III and Table IV, in order to validate the $H$ control. In these tables, the RMS value of the two dominant harmonic components (3rd and 5th orders), the RMS value of the total harmonic current, $I_{H}$, and the Total Harmonic Distortion, THD are included. All the terms collected in these tables are according to the Std. IEEE-1459:2010 [27].

\section{A. Active Power Control}

First, a test has been carried out to validate the $P$ mode operation when charging at nominal power the micro-storage energy system, that is $P_{r e f}=1000 \mathrm{~W}$ (G2B-P mode). In this test, no load current is included $\left(i_{L}=0\right)$, but harmonic distortion in the grid voltage is considered. The fundamental phase-to-neutral grid voltage is $230 \mathrm{~V}$, and the harmonic components are 6\% 5th harmonic and 5\% 7th harmonic. The Total Harmonic Distortion (THD) is $7.81 \%$, complying with the limits proposed in IEC 61000-2-2:2002 [28]. The experimental results are displayed in Fig. 5 and summarized in Table II. Since the set-point is positive, the battery is charging and the battery current is positive. The grid current, which coincides with the charger current, is sinusoidal and in phase with the fundamental component of the grid voltage. One can notice that no harmonic distortion appears in the grid current, although the grid voltage is distorted, and the $d P F$ is unity, so the SC control strategy is operating properly. The active power error is below $4.8 \%$.

\section{B. Active Power and Fundamental Reactive Power Control}

This second test aims to validate the simultaneous operation of the $P$ and $Q$ modes. In this case, the active power set-point is negative $P_{r e f}=-800 \mathrm{~W}$ (B2G-P mode) to test the discharging operation. The fundamental reactive power set point, however, is positive, $Q_{1 \text { ref }}=600 \mathrm{VAr}$, that is, the SCEMS asks the ESS to absorb fundamental reactive power from the grid (G2B-Q mode). Again, the grid voltage is distorted with the same harmonic content as in the previous test and no load current is included.

The results are shown in Fig. 6. In this case, the active power set-point is negative, so the battery is discharging and the battery current is negative. In the ac side, although the grid voltage is distorted, the grid current is sinusoidal with no harmonic distortion. From Table II one can notice that the $d P F$ value is 0.81 , coherent with the active and reactive power set-points and the active and reactive power errors are about $7 \%$ and $10.5 \%$, respectively. From these results, it can be concluded that the SC and QSC control strategies are operating correctly.

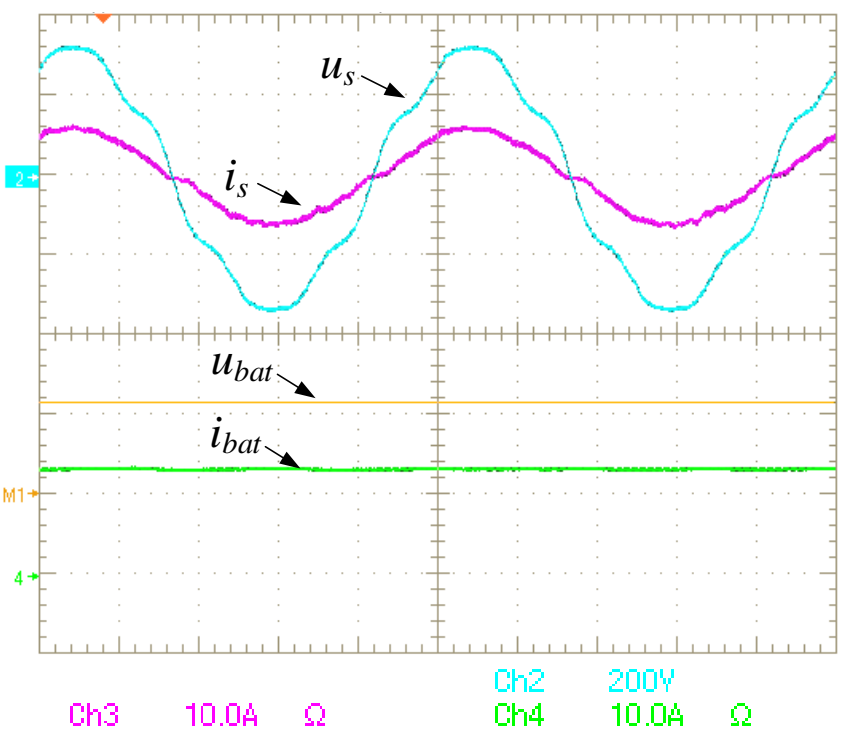

Fig. 5. Experimental results testing the $P$ mode: grid voltage (200 V/div), grid current $(10 \mathrm{~A} / \mathrm{div})$, battery voltage $(50 \mathrm{~V} / \mathrm{div})$ and battery current $(10$ A/div).

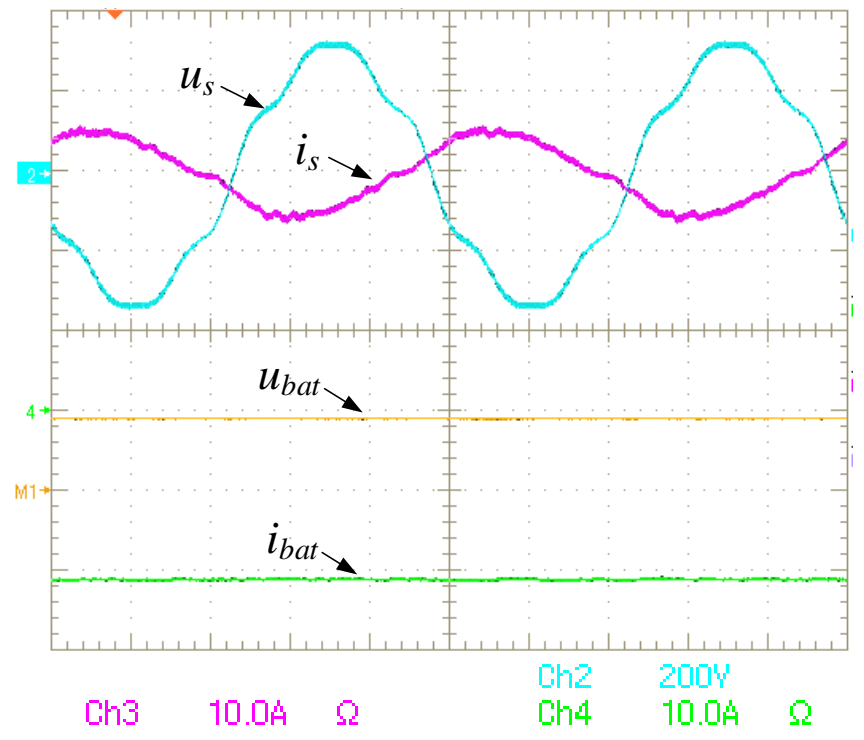

Fig. 6. Experimental results testing the $P$ and $Q$ modes: grid voltage (200 $\mathrm{V} /$ div $)$, grid current $(10 \mathrm{~A} / \mathrm{div})$, battery voltage $(50 \mathrm{~V} / \mathrm{div})$ and battery current (10 A/div).

\section{Active Power, Fundamental Reactive Power and Harmonic Compensation Control}

Finally, the global control strategy with the $P, Q$ and $H$ modes working at the same time is tested. First, an experiment has been conducted to validate the THC control strategy without saturation. Afterwards, experimental conditions have been imposed so that the THC strategy requires saturation in order to not to exceed the nominal conditions of the ESS charger.

These two experimental tests begin without enabling the control of the charger, so $i_{c h}=0$. In this situation, the grid current coincides with the load current. At $t=t_{\text {act }}$, the charger 
control is turned on, operating as stated by the set-points received from the SCEMS and activating the $H$ mode. The grid current now is the sum of the charger current and load current.

The grid voltage is sinusoidal, $230 \mathrm{~V}$ with no harmonic distortion. The RMS current demanded by the non-linear load is $4.45 \mathrm{~A}$. The RMS fundamental component of this current is $3.51 \mathrm{~A}$, so the RMS harmonic component is $I_{L h}=2.73 \mathrm{~A}$.

In the following figures (Fig. 7 and Fig. 8) it is shown, from top to bottom: the grid voltage, grid current, battery voltage and battery current waveforms (before and after the charger activation, at $t=t_{a c t}$ ); the grid current spectrum before activation and after activation, to see in detail the dominant harmonic components.

In the first experiment (Fig. 7), the SCEMS set-points have been fixed to $P_{r e f}=400 \mathrm{~W}$ and $Q_{1 \text { ref }}=200 \mathrm{VAr}$. In this case, $I_{c h-H, \max }=3.89 \mathrm{~A}$, which is greater than $I_{L h}$, so no saturation is needed. The battery current changes from zero to a positive value, since the active power set-point is positive, so the battery is charging. From the grid current spectra and the results of the harmonic components collected in Table III, one can notice that the dominant harmonics of the load current have been practically cancelled in the grid current, so the THC control strategy has operated satisfactorily. The active and reactive power set-points has been quite fulfilled (see Table II), with power errors about $1 \%$ and $10 \%$, respectively, and the $d P F$ is 0.91 , very close to its theoretical value of 0.9 .

In the second test (Fig. 8), the SCEMS set-points have been fixed to $P_{r e f}=900 \mathrm{~W}$ and $Q_{1 r e f}=200$ VAr. Saturation is needed in this case since $I_{c h-H, \max }=1.68 \mathrm{~A}$ is less than $I_{L h}$. The battery current goes again from zero to a positive value, because the battery is charging due to a positive active power set-point. From the harmonic spectra of the grid current before and after the charger activation and the dominant harmonic values of the load, grid and charger currents summarized in Table IV, one can notice that in this case the load current harmonics have only been partially cancelled in the grid current. In conclusion, the THC control strategy has operated properly, saturating the harmonic reference charger to a value that ensures that the charger is not overloaded. From the power terms point of view collected in Table II, the active power error is below $6.8 \%$ and the reactive power error is about $6 \%$, achieving a $d P F$ result coincident with its theoretical value. These results validate the proper operation of the SC and QSC control strategies.

TABLE II

POWER TERMS IN THE EXPERIMENTAL RESULTS

\begin{tabular}{cccccccc}
\hline$P_{\text {ref }}$ & $Q_{1 \text { ref }}$ & $P$ & $Q_{1}$ & $I_{c h}$ & $S$ & $d P F$ & $P F$ \\
$(\mathrm{~W})$ & $(\mathrm{VAr})$ & $(\mathrm{W})$ & $(\mathrm{VAr})$ & $(\mathrm{A})$ & $(\mathrm{VA})$ & & \\
\hline 1000 & 0 & 952 & 25 & 4.16 & 968.6 & 1 & 0.99 \\
-800 & 600 & -743 & 537 & 4.01 & 865.3 & 0.81 & 0.8 \\
400 & 200 & 396 & 180 & 3.28 & 752.9 & 0.91 & 0.53 \\
900 & 200 & 839 & 188 & 4.2 & 964.2 & 0.98 & 0.87 \\
\hline
\end{tabular}

TABLE III

HARMONIC CURRENT COMPONENTS WITHOUT SATURATION

\begin{tabular}{cccccc}
\multicolumn{6}{c}{ HARMONIC CURRENT COMPONENTS WITHOUT SATURATION } \\
\hline$I_{1}(\mathrm{~A})$ & $I_{3}(\mathrm{~A})$ & $I_{5}(\mathrm{~A})$ & $I_{H}(\mathrm{~A})$ & $T H D(\%)$ \\
\hline$i_{L}$ & 3.5 & 2.5 & 1.2 & 2.828 & 80.8 \\
$i_{S}$ & 5.3 & 0.6 & 0.3 & 0.95 & 17.9 \\
$i_{c h}$ & 1.8 & 2.2 & 1.1 & 2.67 & 148.4 \\
\hline
\end{tabular}

TABLE IV

HARMONIC CURRENT COMPONENTS WITH SATURATION

\begin{tabular}{cccccc}
\hline \multicolumn{6}{c}{ HARMONIC CURRENT COMPONENTS WITH SATURATION } \\
\hline$i_{L}$ & $I_{1}(\mathrm{~A})$ & $I_{3}(\mathrm{~A})$ & $I_{5}(\mathrm{~A})$ & $I_{H}(\mathrm{~A})$ & $T H D(\%)$ \\
$i_{S}$ & 3.5 & 2.5 & 1.2 & 2.828 & 80.8 \\
$i_{c h}$ & 7.2 & 1.2 & 0.4 & 1.4 & 19.4 \\
\hline
\end{tabular}

\section{CONCLUSIONS}

A global control strategy for an energy micro-storage system located at a home of a smart community is proposed in this paper. It aims to provide active functions to the community grid, including active power and fundamental reactive power control, operating according to set-points sent by the SCEMS. Additionally, a harmonic control strategy to improve the power quality of the home consumption is presented. This $H$ mode control only comes into operation once the ESMS verifies that the ESS has available capacity and, if necessary, saturates the harmonic load current compensation to ensure that the charger does not exceed its nominal parameters.

The charger contributes to improving the community power quality in two ways: on the one hand, while fulfilling the $P_{r e f}$ and $Q_{1 \text { ref }}$ set-points requested by the SCEMS, it behaves as a sinusoidal current element, injecting or absorbing current from the community grid with no harmonic distortion, even in case of distorted grid voltage. On the other hand, once the active and reactive power set-points are satisfied, if the charger has remaining capacity, it behaves like an active power filter, eliminating or reducing the harmonic components of the current demanded by the home in which it is installed.

The main contributions of the paper are the proposal and experimental validation of a global control strategy which allows the charger to operate simultaneously with $P, Q$ and $H$ control, and the harmonic control strategy with saturated function, to assure the charger safety. An experimental prototype of the ESS charger has been developed and experimental results validating the global control strategy to accomplish the proposed active functions are included. These results demonstrate that local ESS in smart communities can contribute to the smart grid goals.

Currently, the authors are working on extending the topology and control strategies for a charger capable of operating with $P, Q$ and saturated $H$ control in three-phase four-wire distorted and unbalanced smart community grids. 


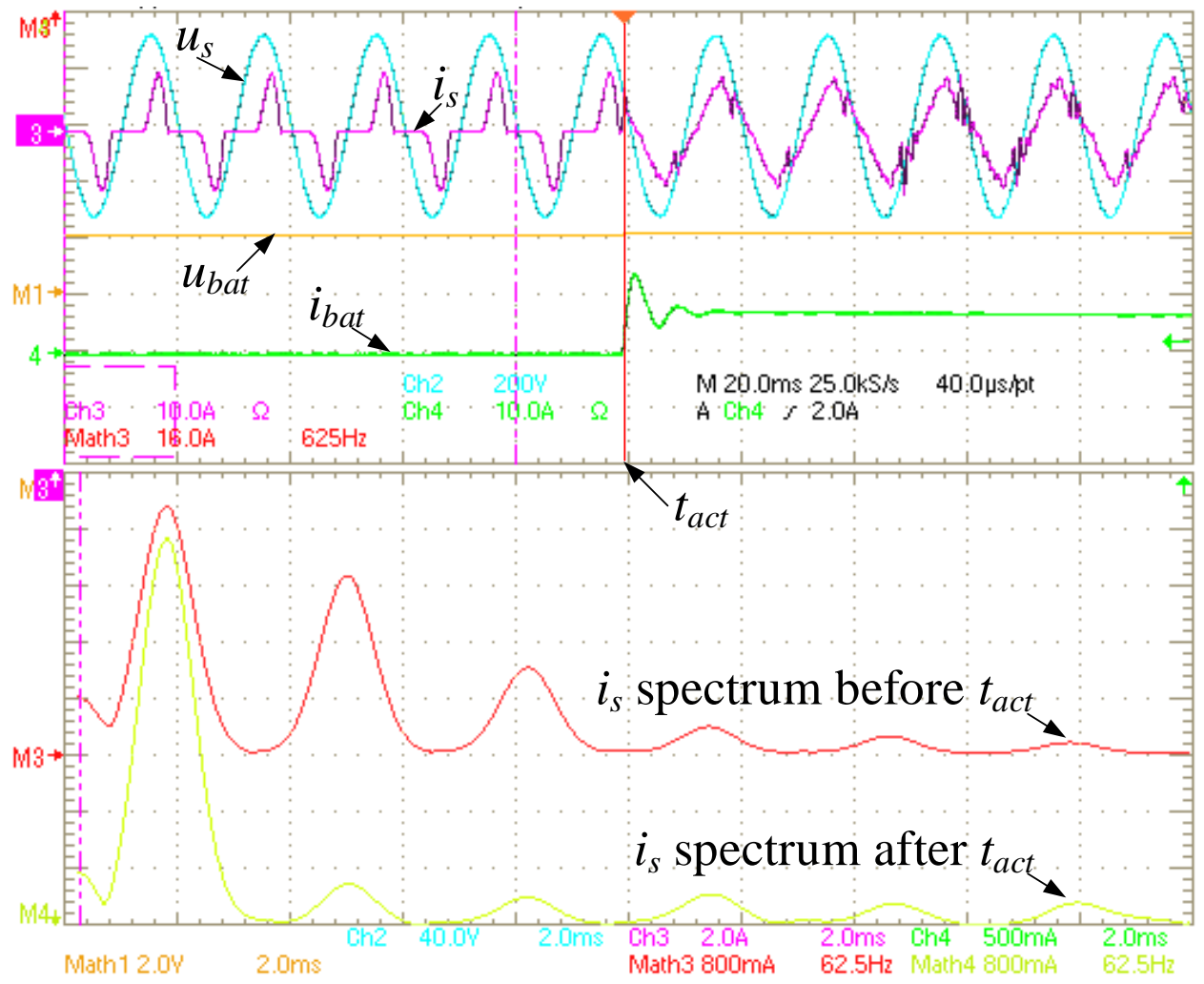

Fig. 7. Experimental results testing the $P, Q$ and $H$ modes without saturation. From top to bottom: grid voltage (200 V/div), grid current (10 A/div), battery voltage (50 V/div) and battery current $(10 \mathrm{~A} / \mathrm{div})$; harmonic spectrum of the grid current before and after the charger activation at $t_{a c t}$.

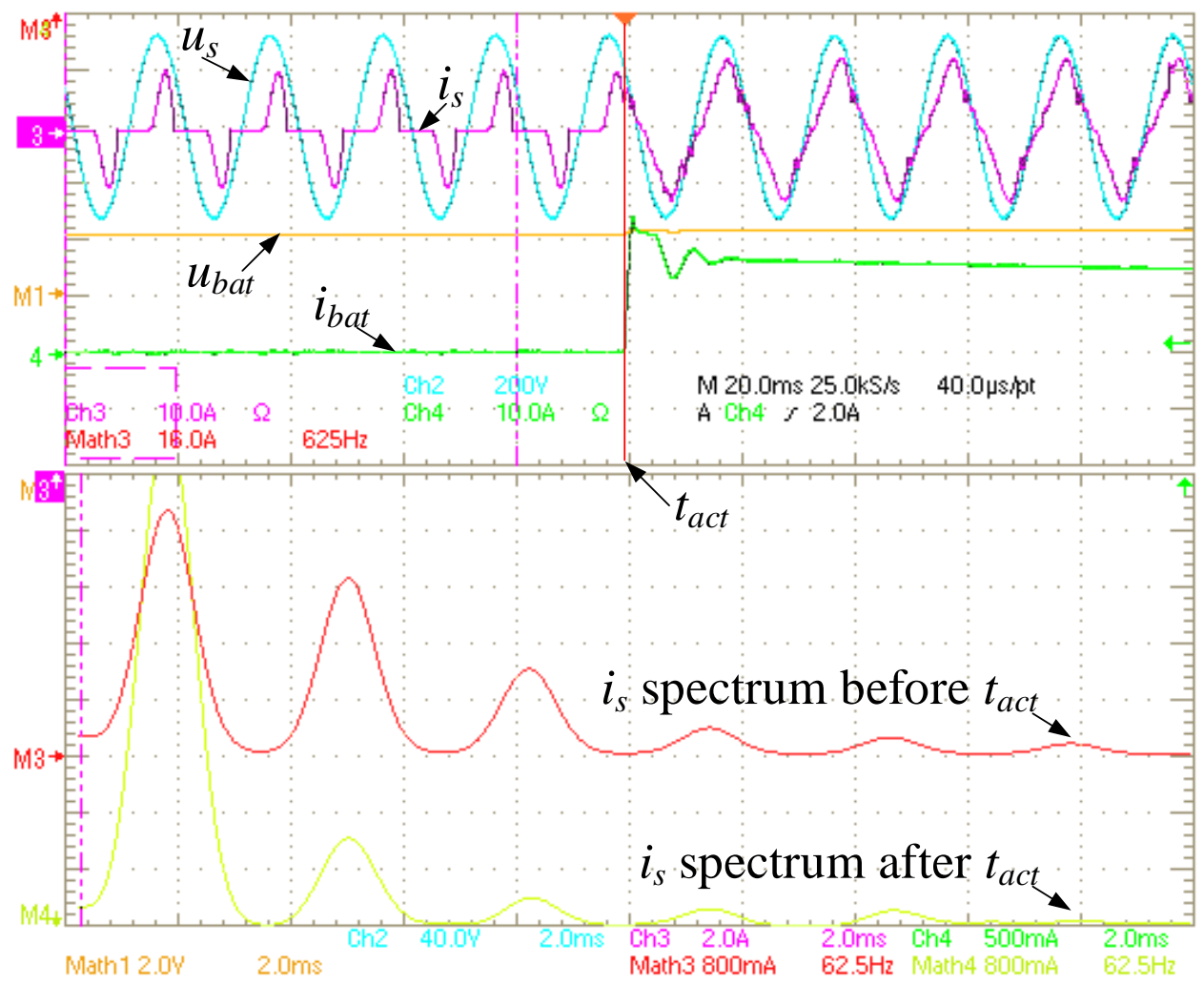

Fig. 8. Experimental results testing the $P, Q$ and $H$ modes with saturation. From top to bottom: grid voltage ( $200 \mathrm{~V} /$ div), grid current (10 A/div), battery voltage $(50 \mathrm{~V} / \mathrm{div})$ and battery current $(10 \mathrm{~A} / \mathrm{div})$; harmonic spectrum of the grid current before and after the charger activation at $t_{\text {act }}$. 


\section{ACKNOWLEDGMENT}

This work was supported by the Spanish Ministerio de Economía y Competitividad and Fondo Social Europeo, FEDER, under Project TEC2013-47316-C3-3-P.

\section{REFERENCES}

[1] R. Davies, M. Sumner, and E. Christopher, "Energy storage control for a small community microgrid," in Proc. 7th IET International Conference on Power Electronics, Machines and Drives (PEMD 2014), pp.1-6, 2014.

[2] L. Sharifi, F. Freitag, and L. Veiga, "Combing Smart Grid with community clouds: Next generation integrated service platform," in Proc. 2014 IEEE International Conference on Smart Grid Communications (SmartGridComm), pp. 434-439, 2014.

[3] J. Li, Z. Wu, S. Zhou, H. Fu, and X.P. Zhang, "Aggregator service for PV and battery energy storage systems of residential building," CSEE Journal of Power and Energy Systems, vol. 1, no. 4, pp. 3-11, 2015.

[4] C. J. Mozina, "Impact of smart grids and green power generation on distribution systems," IEEE Transactions on Industry Applications, vol. 49, no. 3, pp. 1079-1090, May/Jun. 2013.

[5] H. Kanchev, D. Lu, F. Colas, V. Lazarov, and B. Francois, "Energy management and operational planning of a microgrid with a PV-based active generator for smart grid applications," IEEE Transactions on Industrial Electronics, vol. 58, no. 10, pp. 4583-4592, 2011.

[6] E. González-Romera, F. Barrero-González, E. Romero-Cadaval, and M.I. Milanés-Montero, "Overview of plug-in electric vehicles as providers of ancillary services," in Proc. 9th Int. Conf. Compatibility and Power Electronics (CPE 2015), 2015.

[7] S. A. Saleh, P. Pijnenburg and E. Castillo-Guerra, "Load Aggregation From Generation-Follows-Load to Load-Follows-Generation: Residential Loads", IEEE Transactions on Industry Applications, vol. 53, no. 2, pp. 833-842, March/April 2017.

[8] S. Aman, Y. Simmhan, and V.K. Prasanna, "Energy management systems: state of the art and emerging trends," IEEE Communications Magazine, vol. 51, pp. 114-119, 2013.

[9] R. C. Dugan, J. A. Taylor and D. Montenegro, "Energy Storage Modeling for Distribution Planning", IEEE Transactions on Industry Applications, vol. 53, no. 2, pp. 954-962, March/April 2017.

[10] M. Farhadi and O. Mohammed, "Energy storage technologies for highpower applications," IEEE Transactions on Industry Applications, vol. 52, no. 3, pp. 1953-1961, May-June 2016.

[11] A. A. Hussein, N. Kutkut, Z. J. Shen, and I. Batarseh, "Distributed battery micro-storage systems design and operation in a deregulated electricity market," IEEE Transactions on Sustainable Energy, vol. 3, no. 3, pp. 545-556, July 2012.

[12] K. Panagiotou, C. Klumpner and M. Sumner, "Being a member of an energy community: Assessing the financial benefits for end-users and management authority," in Proc. IEEE 26th International Symposium on Industrial Electronics (ISIE 2017), pp. 957-963, 2017.

[13] J. Gallardo-Lozano, M. I. Milanés-Montero, M. A. Guerrero-Martínez, and E. Romero-Cadaval, "Three-phase bidirectional battery charger for smart electric vehicles," in Proc. 7th International ConferenceWorkshop Compatibility and Power Electronics (CPE 2011), Tallinn, 2011, pp. 371-376.

[14] J. C. Gomez and M. M. Morcos, "Impact of EV battery chargers on the power quality of distribution systems," IEEE Transactions on Power Delivery, vol. 18, no. 3, pp. 975-981, 2003.
[15] X. Liang, "Emerging Power Quality Challenges Due to Integration of Renewable Energy Sources", IEEE Transactions on Industry Applications, vol. 53, no. 2, pp. 855-866, March/April 2017.

[16] O. C. Onar and A. Khaligh, A., "Grid interactions and stability analysis of distribution power network with high penetration of plug-in hybrid electric vehicles," in Proc. 25th Annual IEEE Applied Power Electronics Conference and Exposition (APEC), pp. 1755-1762, 2010.

[17] C. Roncero-Clemente, O. Husev, E. Romero-Cadaval, J. Martins, D. Vinnikov, and M.I. Milanés-Montero. "Three-phase three-level neutralpoint-clamped qZ source inverter with active filtering capabilities," in Proc. 9th International Conference-Workshop Compatibility and Power Electronics (CPE 2015), pp. 216-220. Caparica, Portugal. June 2015.

[18] V. Miñambres-Marcos, E. Romero-Cadaval, M. Á. Guerrero-Martínez, and M. I. Milanés-Montero, "Three-phase single stage photovoltaic inverter with active filtering capabilities," in Proc. 38th Annual Conference on IEEE Industrial Electronics Society, IECON 2012, pp. 5253-5258. Montreal, QC, 2012.

[19] H. Fakham, D. Lu, and B. Francois, "Power control design of a battery charger in a hybrid active PV generator for load-following applications," IEEE Transactions on Industrial Electronics, vol. 58, no. 1, pp. 85-94, Jan. 2011.

[20] M. C. Kisacikoglu, B. Ozpineci, and L. M. Tolbert, "EV/PHEV bidirectional charger assessment for V2G reactive power operation," IEEE Transactions on Power Electronics, vol. 28, no. 12, pp. 57175727, Dec. 2013

[21] D. B. Wickramasinghe Abeywardana, B. Hredzak, and V. G. Agelidis, "A fixed-frequency sliding mode controller for a boost-inverter-based battery-supercapacitor hybrid energy storage system," IEEE Transactions on Power Electronics, vol. 32, no. 1, pp. 668-680, Jan. 2017.

[22] M. I. Milanés-Montero, E. González-Romera, F. Barrero-González, E. Romero-Cadaval, and A. Moreno-Munoz, "Local energy micro-storage systems in smart communities with active, reactive and harmonic control," in Proc. 2016 IEEE 16th International Conference on Environment and Electrical Engineering (EEEIC), pp. 1-5. Florence, Italy, 2016.

[23] M. I. Milanés-Montero, J. Gallardo-Lozano, E. Romero-Cadaval, and E. González-Romera, "Hall-effect based semi-fast AC on-board charging equipment for electric vehicles," Sensors, vol. 11, no. 10, pp. 9313-9326, 2011.

[24] M. I. Milanes-Montero, E. Romero-Cadaval, A. R. de Marcos, V. M. Minambres-Marcos, and F. Barrero-Gonzalez, "Novel method for synchronization to disturbed three-phase and single-phase systems," in Proc. 2007 IEEE International Symposium on Industrial Electronics, pp. 860-865. 2007.

[25] M. Manbachi, H. Farhangi, A. Palizban and S. Arzanpour, "Community Energy Storage impacts on smart grid adaptive Volt-VAR Optimization of distribution networks," in Proc. IEEE 7th International Symposium on Power Electronics for Distributed Generation Systems (PEDG 2016), pp. 1-8. 2016.

[26] J. Miret, M. Castilla, J. Matas, J. M. Guerrero, and J. C. Vasquez. "Selective harmonic-compensation control for single-phase active power filter with high harmonic rejection," IEEE Trans Ind. Electron, vol. 56, no. 8, pp. 3117-3127, 2009.

[27] IEEE Standard Definitions for the Measurement of Electric Power Quantities under Sinusoidal, Nonsinusoidal, Balanced, or Unbalanced Conditions, Std. IEEE 1459:2010. 2010.

[28] Electromagnetic compatibility (EMC) - Part 2-2: environment compatibility levels for low-frequency conducted disturbances and signalling in public low-voltage power supply systems, IEC Technical Committee 77A. IEC 61000-2-2:2002. 2002. 